\title{
Sacral nerve stimulation for constipation: history of an unconsummated marriage
}

\author{
J. Martellucci $^{1}$
}

Received: 5 April 2017/Accepted: 6 April 2017/Published online: 3 May 2017

(C) Springer International Publishing AG 2017

The turbulent love story between sacral nerve modulation (SNS) and constipation was started by accident, from anecdotal reports of relevant benefits in patients that underwent SNS for urinary dysfunction.

The first data, which were published by the St. Marks group in 2002, were obtained from 2 partially overlapping groups of 8 and 4 patients, most of whom had slow transit constipation demonstrated by transit study, and were corroborated by a double-blind placebo-controlled crossover study on an impressive number of 2 patients. Despite the great interest in this topic, the large number of presentations and posters which can be found in every colorectal congress, and the increasing knowledge about SNS effects and mechanisms of action, it took 6 years before a second paper about this topic was published (2008) and 13 years before a second controlled trial was performed (this time with 59 patients). Until this last trial the Cochrane reviews were based on only 2 patients.

To date there is still a paucity of reports on this topic with less than one paper published per year, and data about less than 400 patients are available, with very inconsistent results. Moreover, the success threshold conventionally established at 50\% and the variable inclusion criteria, putting patients with slow transit, normal transit, or obstructed defecation due to anatomical or functional alterations all together made these results extremely difficult to evaluate and compare.

J. Martellucci

jamjac64@hotmail.com

1 General, Emergency and Mininvasive Surgery, Careggi University Hospital, Largo Brambilla 3, 50134 Florence, Italy
This year, marking the 15th anniversary of this love story between SNS and constipation, 3 papers including the one in this issue of Techniques in Coloproctology [1] reported poor long-term results about SNS for constipation (slow transit only), seeming to set the stage for a divorce.

But are we really sure that everything in this story has already been said? Are we really sure that after the analysis of a few heterogeneous patients we can just say "hic sunt dracones" and stay away?

Why is it that every time selection criteria become more rigid, for example, selecting only patients with slow transit constipation with a normal psychological profile or only patients with rectal evacuatory dysfunction and rectal hyposensitivity, the results of SNS are amazingly better $(>80 \%)$ ? [2, 3].

Why can SNS change rectal sensitivity and biomechanical rectal properties, in patients with irritable bowel syndrome, or increase pancolonic motor response in patients with slow transit constipation, but only at a suprasensory threshold and without improving the frequency of bowel movements? [4-6].

Why does it seem that performing SNS after a complete bowel preparation could result in better outcomes? [7].

Even if slow transit constipation (however it id defined) cannot be cured by SNS alone because of other factors other forms of constipation deserve to be explored more carefully. Rectal evacuatory dysfunction, especially when the functional alterations prevail over anatomical ones, post-surgical constipation, constipation related to neurological disease, constipation and endometriosis, constipation and inflammatory bowel disease, constipation as part of low anterior resection syndrome, can also be indications for SNS. In conclusion, the love story between SNS and constipation should not end after the first quarrel. 
Maybe the problem is not our use of SNS but our knowledge about constipation itself...

\section{Compliance with ethical standards}

Conflict of interest The author declares that he has no conflict of interest.

Ethical approval This article does not contain any studies with human participants or animals performed by any of the authors.

\section{Informed consent None.}

\section{References}

1. Maeda Y, Kamm MA, Vaizey CJ, Matzel KE, Johansson C, Rosen H, Baeten CG, Laurberg S (2017) Long term outcome of sacral neuromodulation for chronic refractory constipation. Tech Coloproctol. doi:10.1007/s10151-017-1613-0

2. Carriero A, Martellucci J, Talento P, Ferrari CA (2010) Sacral nerve stimulation for constipation: do we still miss something?
Role of psychological evaluation. Int $\mathrm{J}$ Colorectal Dis 25:1005-1010

3. Knowles CH, Thin N, Gill K, Bhan C, Grimmer K, Lunniss PJ et al (2012) Prospective randomized double-blind study of temporary sacral nerve stimulation in patients with rectal evacuatory dysfunction and rectal hyposensitivity. Ann Surg 255:643-649

4. Fassov J, Brock C, Lundby L, Drewes AM, Gregersen H, Buntzen S, Laurberg S, Krogh K (2014) Sacral nerve stimulation changes rectal sensitivity and biomechanical properties in patients with irritable bowel syndrome. Neurogastroenterol Motil 26:1597-1604

5. Dinning PG, Hunt LM, Arkwright JW, Patton V, Szczesniak MM, Wiklendt L, Davidson JB, Lubowski DZ, Cook IJ (2012) Pancolonic motor response to subsensory and suprasensory sacral nerve stimulation in patients with slow-transit constipation. $\mathrm{Br} \mathrm{J}$ Surg 99:1002-1010

6. Dinning PG, Hunt L, Patton V, Zhang T, Szczesniak M, Gebski V, Jones M, Stewart P, Lubowski DZ, Cook IJ (2015) Treatment efficacy of sacral nerve stimulation in slow transit constipation: a two-phase, double-blind randomized controlled crossover study. Am J Gastroenterol 110:733-740

7. Martellucci J, Naldini G (2013) Role of preoperative bowel preparation before sacral nerve modulation for constipation. Colorectal Dis 15:1451 